\title{
Estimation of Influence of Explosive Characteristics of Emulsion Explosives on Shotpile Width
}

\author{
Victor Sinitsyn ${ }^{1 *}$, Pavel Menshikov ${ }^{1}$ and Vyacheslav Kutuev ${ }^{1}$ \\ ${ }^{1}$ Institute of Mining, Ural Branch of the Russian Academy of Sciences, Ekaterinburg, Russia.
}

\begin{abstract}
The article deals with the question of the effect of explosive characteristics of emulsion explosives on the shotpile width. Currently, there are two main points of view to select an efficient type of explosive, which contributes to the qualitative destruction (fragmentation) of coarse clastic rocks. The first is based on the assumption that the detonation velocity of explosives must correspond to the break-down point of the rock (dynamic compression). Another point of view is that the detonation pressure of explosives determines only the head part of the pulse, on which the rock fragmentation is dependent only near the charge, in the contact zone around the borehole. The fragmentation of the entire rock volume within a given borehole array depends on the total magnitude of the explosion pulse, determined not by the detonation velocity, but by the total energy reserve of the explosive charge. Experimental explosions with some of the most common industrial explosives have been carried out in the current conditions of blasting of borehole charges by various types of industrial explosives from the point of view to select the most important parameter, which determines its influence on the shotpile width The investigations have been carried out according to the data obtained to establish that the energy properties of explosives (heat of explosive transformation and density of explosives) determine the decisive influence on the shotpile width, and the operability, the volume of the released gases, the detonation velocity for the change in the shotpile width have very little effect and may not be taken into account in calculations for the prediction of the shotpile.
\end{abstract}

\section{Introduction}

Explosives used for the destruction of rocks are, for the most part, a mixture of two or more components. One of the directions is the influence of explosive characteristics on the shotpile width and the definition of the most important of them, which are necessary for an efficient explosion $[1,2]$.

Explosive destruction of rocks is a very complicated phenomenon. One of the main tasks of breaking rocks is the separation of the rock from the rock mass with its simultaneous crushing into pieces of a certain size and a compact arrangement of them on

\footnotetext{
*Corresponding author: slavik1988@mail.ru
} 
the bottom of the ledge. The effect of the explosion in the medium and the intensity of crushing of rocks depend on many factors that characterize both the properties of the medium and the properties of explosives, as well as the conditions of explosion, in particular, the parameters of borehole breakdown. The selection of the type of explosives and the prediction of the optimal parameters of drilling and blasting operations on a particular physical model of the action of the explosion of a borehole charge. Such models are built on the basis of general laws of continuum mechanics taking into account experimental data. The medium is usually characterized as isotropic with physicomechanical properties averaged over the whole volume [3, 4].

\section{Theory}

Currently, there are two main points of view to select an efficient type of explosive, which contributes to the qualitative destruction (fragmentation) of coarse clastic rocks. The first is based on the assumption that the detonation velocity of explosives must correspond to the break-down point of the rock (dynamic compression). The criterion for this indicator is the ratio of the impedances of explosives and rocks, which should be as close as possible to unity. Another point of view is that the detonation pressure of explosives determines only the head part of the pulse, on which the rock fragmentation is dependent only near the charge, in the contact zone around the borehole. The fragmentation of the entire rock volume within a given borehole array depends on the total magnitude of the explosion pulse, determined not by the detonation velocity, but by the total energy reserve of the explosive charge. In the matter of the effect of explosive characteristics of explosives on the shotpile width there are many more different opinions $[4,5]$.

Experimental explosions with some of the most common industrial explosives have been carried out in the present conditions of blasting of borehole charges by various types of industrial explosives from the point of view to select the most important parameter, which determines its influence on the shotpile width (Table 1). Of course, all the above explosive characteristics of explosives are interrelated and a decrease or increase in one of them can lead to a change in the other. However, under the standard conditions of charge explosion, which are sought to be as close as possible in the production conditions of explosion, the characteristics of explosives [4] are practically constant values, usually determined by reference books or technical specifications [5-7].

The accuracy of the experimental determination of the heat of explosion depends on the conditions of the explosion (the diameter of the charge, the material and the thickness of the shell), the dispersity of the components and the uniformity of their mixing, the density of explosives and many other factors. 
Table 1. Explosive characteristics of some of the most common industrial explosives

\begin{tabular}{|c|c|c|c|c|c|c|}
\hline 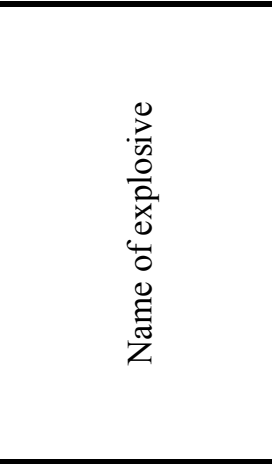 & 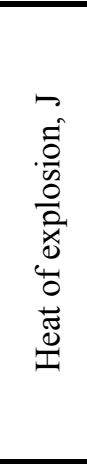 & 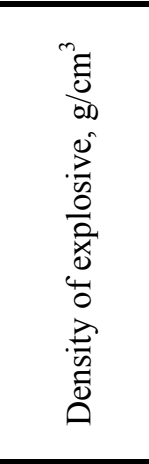 & 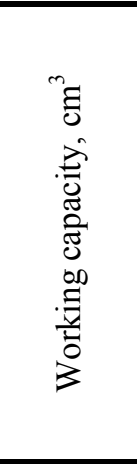 & 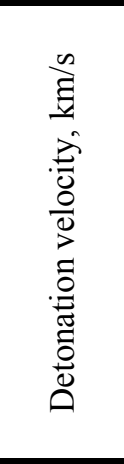 & 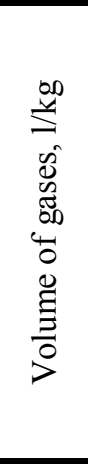 & 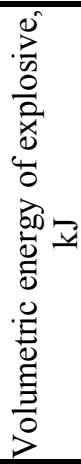 \\
\hline Granulotol & 4100 & $0.95-1.0$ & 290 & $5.5-6.5$ & 1945 & 3895 \\
\hline Grammonit 79/21 & 4300 & $0.9-0.95$ & 360 & $3.5-4.2$ & 850 & 4085 \\
\hline Ammonite 6ZhV & 4300 & $0.9-0.95$ & $360-380$ & $3.6-4.8$ & 895 & 4085 \\
\hline Igdanit 94/6 & 3300 & $0.8-0.85$ & $320-330$ & $2.2-2.7$ & 990 & 3230 \\
\hline Iphzanite T-20 & 3300 & $1.34-1.38$ & 290 & $4.2-4.5$ & 937 & 4488 \\
\hline Poramit & 3200 & $1.25-1.35$ & $300-310$ & $4.5-5.0$ & 890 & 4160 \\
\hline
\end{tabular}

\section{Results}

Below are the results of an experimental determination of the heat of explosion (relative operability) of some industrial explosives (Table 2).

Table 1. Experimental and calculated values of the heat of explosion for various explosives

\begin{tabular}{|c|c|c|c|c|c|}
\hline \multirow{2}{*}{ Explosive } & \multirow{2}{*}{$\begin{array}{c}\text { Oxygen } \\
\text { balance, } \%\end{array}$} & \multicolumn{2}{|c|}{ Heat of explosion, kcal/kg } & \multirow{2}{*}{$\begin{array}{c}\text { Density } \\
\text { g/cm }\end{array}$} \\
\cline { 5 - 6 } & & $\mathrm{Q}_{\max }$ & $\mathrm{Q}_{\mathrm{v}}$ & $\mathrm{Q}_{\mathrm{ex}}$ & \\
\hline TNT & -74 & 1300 & $985-1000$ & 850 & 0.85 \\
\hline «-» & -74 & 1300 & $985-1000$ & $1000-1160$ & $1.5-1.6$ \\
\hline Hexogen & -22 & 1510 & $1240-1330$ & $1270-1325$ & $1.5-1.6$ \\
\hline Ten & -10 & 1550 & 1405 & 1400 & $1.5-1.6$ \\
\hline TNT/hexogen (50/50) & -48 & 1405 & 1146 & 1140 & $1.5-1.6$ \\
\hline Granulotol & -74 & 1300 & 975 & 870 & 1 \\
\hline Alumotol & -76.2 & 1831 & 1260 & 1130 & 1.1 \\
\hline Zernogranulite 30/70 & -45.9 & 1200 & 950 & 870 & $1-1.1$ \\
\hline Zernogranulite 50/50 & -27.5 & 1120 & 985 & 910 & $0.9-1$ \\
\hline Zernogranulite 79/21 & 0 & 1030 & 1030 & 967 & $0.9-1$ \\
\hline Granulite AC-8 & +0.3 & 1242 & 1242 & 1260 & $0.9-1$ \\
\hline Granulite AC-4 & +0.4 & 1080 & 1080 & 1128 & $0.9-1$ \\
\hline Granulite M & +0.1 & 920 & 920 & 904 & $0.9-1$ \\
\hline Aquatol 65/35 & -12.5 & 837 & 767 & 707 & 1.45 \\
\hline Aquatol M-15 & -21 & 1366 & 1167 & 1107 & 1.4 \\
\hline Thunnnnn
\end{tabular}

Thus, on the basis of the studies carried out, it is possible to draw conclusions that are very important for practical application: 
- the energy properties of explosives (the heat of explosive transformation and the density of explosives) are critical for the shotpile width;

- the operability, the volume of released gases, the detonation velocity for the change in the shotpile width have a very small effect and can not be taken into account in calculations for the prediction of the shotpile.

The design characteristics of explosives in boreholes for carrying out experimental explosions at the open-pit mines of the Pervouralskoe Mine Administration are given in Table 3.

Table 3. Results of statistical comparison of measurement data for the shotpile width with basic characteristics of explosives

\begin{tabular}{|c|c|c|c|c|c|c|}
\hline Comparable values & 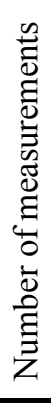 & 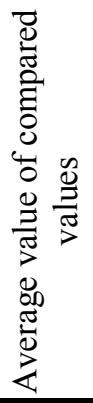 & 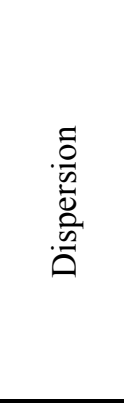 & 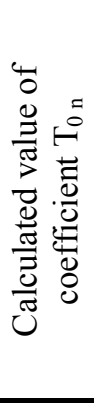 & 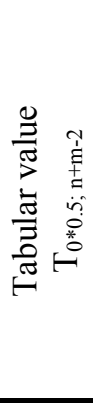 & 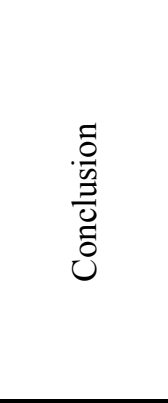 \\
\hline \multirow[t]{2}{*}{ Working capacity, $\mathrm{cm}^{3}$} & 7 & 303 & 100.4 & \multirow{2}{*}{10.89} & \multirow{2}{*}{2.18} & \multirow{2}{*}{$\begin{array}{l}\text { Significant } \\
\text { difference }\end{array}$} \\
\hline & 7 & 311 & 53.2 & & & \\
\hline \multirow[t]{2}{*}{ Detonation velocity, $\mathrm{m} / \mathrm{s}$} & 7 & 5132 & 988 & \multirow{2}{*}{10.13} & \multirow{2}{*}{2.18} & \multirow{2}{*}{$\begin{array}{l}\text { Significant } \\
\text { difference }\end{array}$} \\
\hline & 7 & 3663 & 4015 & & & \\
\hline \multirow[t]{2}{*}{ Volume of gases, $1 / \mathrm{kg}$} & 7 & 1743 & 3726 & \multirow{2}{*}{10.37} & \multirow{2}{*}{2.18} & \multirow{2}{*}{$\begin{array}{l}\text { Significant } \\
\text { difference }\end{array}$} \\
\hline & 7 & 940 & 1868 & & & \\
\hline \multirow[t]{2}{*}{ Heat of explosion, $\mathrm{J}$} & 7 & 4136 & 851 & \multirow{2}{*}{10.92} & \multirow{2}{*}{2.18} & \multirow{2}{*}{$\begin{array}{l}\text { Significant } \\
\text { difference }\end{array}$} \\
\hline & 7 & 4284 & 435 & & & \\
\hline \multirow[t]{2}{*}{ Load density of explosive, $\mathrm{g} / \mathrm{cm}^{3}$} & 7 & 0.966 & 0.00004 & \multirow{2}{*}{8.25} & \multirow{2}{*}{2.18} & \multirow{2}{*}{$\begin{array}{c}\text { Significant } \\
\text { difference }\end{array}$} \\
\hline & 7 & 0.935 & 0.00005 & & & \\
\hline \multirow{2}{*}{$\begin{array}{l}\text { Volumetric energy of explosive, } \\
\mathrm{J} / \mathrm{kg}\end{array}$} & 7 & 3998 & 72 & \multirow{2}{*}{0.76} & \multirow{2}{*}{2.18} & \multirow{2}{*}{$\begin{array}{c}\text { Significant } \\
\text { difference }\end{array}$} \\
\hline & 7 & 4002 & 1156 & & & \\
\hline \multirow[t]{2}{*}{ Shotpile width, m } & 7 & 21.7 & 4.23 & \multirow{2}{*}{0.71} & \multirow{2}{*}{2.18} & \multirow{2}{*}{$\begin{array}{l}\text { Significant } \\
\text { difference }\end{array}$} \\
\hline & 7 & 22.6 & 4.49 & & & \\
\hline
\end{tabular}

The values of the explosive characteristics of the emulsion explosives in the boreholes and the measurements of the shotpile width were compared among themselves in pairs by the Student-Gorset criterion. Calculation of the Student-Gorset design criteria was performed by comparing them with a tabular account of the significance level ta) 0.05 and the degree of freedom $n_{1}+n_{2}=2[8,9]$.

\section{Conclusions}

The obtained experimental parameters allow to establish the compliance of explosives with quality control standards, technical conditions and optimize rational parameters of drilling and blasting operations.

The research has been carried out within the framework of the State Proposal 00700293-18-00, themes No. 0405-2018-0015, No. 0405-2018-0001, project No. 18-5-5-10, as well as with additional attraction of contractual means. 


\section{References}

1. B. N. Kutuzov, Rock Disintegration by Explosion, (Moscow, 1992) 516 pp. [In Russian].

2. E. V. Bashkuev, V. F. Bogatsky et al., Engineering of Blasting Operations in Industry, (Moscow, 1983) 359 pp. [In Russian].

3. V. N. Rozhdestvenskii, Investigation of Ways to Control Shotpile during Blasting Rocks in Open-Pit Mines, (Yekaterinburg, 1997) 197 pp. [In Russian].

4. A. N. Khanukaev, Physical Processes during Rock Breaking by Explosion, (Moscow, 1974) [In Russian].

5. N. V. Melnikova, Theory and Practice of Open Development, (Moscow, 1974) 144 pp. [In Russian].

6. V. A. Sinitsyn, Increase in Efficiency of Preparation of Rock Mass in Open-Pit Mines with Use of Explosives Based on Inverse Emulsions, (Ekaterinburg, 2007) 143 pp. [In Russian].

7. A. A. Kushko, Research and Development of Methods to Control Parameters of Shotpile during Explosive Rock Breaking, (Krivoy Rog, 1976) 24 pp. [In Russian].

8. L. Z. Rumishsky, Mathematical Treatment of Experimental Results, (Moscow, 1974) 194 pp. [In Russian].

9. E. S. Wenzel, V. A. Ovcharov, Probability Theory and its Engineering Applications, (Moscow, 1982) 480 pp. [In Russian]. 